\title{
The IIIness Perception and its Association with Distress in Cancer Patients Receiving Chemotherapy
}

\author{
(D) Havva YEŞiL ÇINKIR, ${ }^{1}$ (D) Gülçin ELBOĞA² \\ 'Department of Medical Oncology, Gaziantep University Faculty of Medicine, Gaziantep-Turkey \\ ${ }^{2}$ Department of Psychiatry, Gaziantep University Faculty of Medicine, Gaziantep-Turkey
}

\begin{abstract}
OBJECTIVE
Long treatment periods, repeated hospitalizations and side effects of chemotherapy besides the knowledge of having cancer may all affect the psyche of these patients. In this study, we investigated the effects of illness perception on anxiety and depression in cancer patients receiving chemotherapy treatment.

\section{METHODS}

A total of 182 patients were recruited in this cross-sectional study. Hospital Anxiety Depression Scale, Visual Analoge Scale and Brief Illness Perception Questionnaire were used to assess the anxiety and depression, pain and illness perception, respectively.

\section{RESULTS}

There were 103 (56.59\%) female and 79 (43.41\%) male patients in this study. The present sample had possible clinical levels of anxiety and depression of $25.3 \%$ and $26.4 \%$, respectively, and probable clinical levels of anxiety and depression of $25.8 \%$ for both. Positive illness perception parameters, such as personal control and treatment control, were both not correlated with anxiety scores $(p=0.120, p=0.070$, respectively). According to the evaluation of depression scores, personel control was negatively correlated $(\mathrm{p}<0.005)$ and no relation was found to treatment control $(\mathrm{p}=0.062)$. VAS was positively correlated with negative illness perception $(\mathrm{p}<0.005)$.
\end{abstract}

\section{CONCLUSION}

Anxiety and depression were strongly associated with illness perception and pain in cancerpatients during chemotherapy treatment. Oncologists and chemotherapy nurses should pay more attentive to the signs and symptoms of anxiety and depression, and offer specific supportive therapy to each patient.

Keywords: Anxiety; chemotherapy; depression; illness perception.

Copyright $\odot$ 2020, Turkish Society for Radiation Oncology

\section{Introduction}

Cancer treatment has three main modalities, namely surgery, radiotherapy and chemotherapy. The chemotherapy is an intense and a cyclic treatment and has many side effects, such as hair loss, nausea, vomiting, loss of appetite, diare and immunsuppression. Long treatment periods, recurrent hospitalizations, and the side effects of chemotherapy, in addition to the knowledge of cancer, affect the psyche of the patients.

Depression and anxiety affect $20 \%$ and $10 \%$ of the cancer patients receiving curative or palliative treatment, respectively.[1] Two-thirds of patients with cancer and depression also have clinically significant anx- 
iety.[2] Depression rates vary according to the type of cancer. Lung cancer (13\%), gynecologic cancer (11\%), breast cancer $(9 \%)$, colorectal cancer $(7 \%)$ and genitourinary system cancer $(6 \%)$ are the most common. [3] The highest levels of anxiety are reported in lung, gynecologic and hematological cancers. [4] This difference between types of cancer is thought to be related to the prognosis of patients, pain levels and body image changes, in addition to disease-specific neuropsychiatric effects and treatment-related neuropsychiatric side effects.[2]

Pain is one of the symptoms that negatively affect the quality of life in cancer patients and causes the patient to develop secondary problems concerning physical, psychological and sociological aspects. The pain leads to negative effects not only on the patient but also on the close environment. In the recognition and treatment of pain, it is necessary to consider the emotional, cognitive and behavioral dimensions, as well as the perceptual aspect. Pain may sometimes be a symptom of a psychiatric disorder, and sometimes as a physical disorder leads to a disorder in the person's spiritual world. Although the factors involved in the occurrence of pain are largely similar in most people, it is noteworthy that past experiences, social and psychological factors determine the response to pain and vary considerably between individuals.

Anxiety symptoms, such as motor tension, persistent danger and immediate startle, displeasure and fearful waiting, are common in painful patients. Therefore, it should be considered that psychological factors play an important role in pain severity and continuity in individuals with cancer pain.[5]

Illness perception was proposed to be one of the significant causes of psychological distress in cancer patients in the early follow-up period.[6] However, few researchers have examined the relationship between patients' illness and treatment beliefs or causal attributions of symptoms and distress during the treatment phase in cancer patients. In one study, it was reported that distress during the treatment phase was associated with more negative illness beliefs and a likelihood of reporting more severe side effects. [7] However, cancer differs from other chronic illnesses in that its treatment often produces more symptoms than does the illness itself. In this study, we aimed to investigate the effects of illness perception on anxiety and depression in cancer patients receiving chemotherapy treatment.

\section{Materials and Methods}

\section{Sample and Settings}

This study was conducted at a single center-Gaziantep University Faculty of Medicine, Oncology Hospital. The protocol and informed consent documentation were reviewed and approved by the Independent Ethics Committee of the University and agreed with the ethical principles of the Declaration of Helsinki. In total, 182 patients who were receiving chemotherapy in our hospital between March 1, 2019, and March 31, 2019 , were included in this cross-sectional study. The inclusion criteria for the patients were as follows: (1) 18 years and over (2) having a histopathologically proven cancer diagnosis (3) receiving intravenous chemotherapy and (4) no obvious mental abnormalities, psychological disorder, and cognitive impairment. The exclusion criteria were as follows: (1) have not agreed to participate in this study and (2) non-communicable patients. The following information was recorded: age, gender, marital status, educational level, working status, diagnosis of cancer subtype and disease stage.

\section{Study Measures}

Participants completed a standardized questionnaire assessing the socio-demographic factors, degree of pain, anxiety and depression, and illness perception. Thus, the following measures were used:

\section{Socio-Demographic Characteristics}

We developed the socio-demographic and medical questionnaire to assess general information (e.g. age, gender, education level and employment status), personal information about patient's relationships with their partners (e.g. marital status), and general information about their cancer diagnosis (e.g. type of diagnosis, disease's stage).

Visual Analogue Scale (VAS): The VAS was a straight horizontal, $10 \mathrm{~cm}$ line and was anchored on the left with "no pain" and on the right with "pain as bad as it could be." The patient reported pain intensity by drawing a vertical mark at the appropriate interval on the horizontal line. The pain intensity score was determined by measuring the distance, in millimeters, from the left side of the line to the place marked by the patient. The VAS is considered to be one of the beststudied pain intensity scales concerning validity, reliability, and sensitivity.[8]

The Hospital Anxiety and Depression Scale (HADS): HADS was developed in 1983 by Zigmond et al.[9] HADS is a 14-item scale which is divided into 
two dimensions-anxiety (seven items-question 1, 3, 5, $7,9,11,13$ ) and depression (seven items-question-2, $4,6,8,10,12,14)$. The items are scored from 0 to 3 , with higher scores indicating greater levels of anxiety and depression. The scale distinguishes between probable and possible pathology-a score of between 0 and 7 indicates normal situation, 8 and 10 indicates possible pathology (borderline), and a score between 11 and 21 indicates probable pathology (abnormally). The HADS has been validated among a population of people with cancer [10] and is the most frequently used screening tool for psychological distress in cancer care. In our study, we used the Turkish version, which was adapted by Aydemir et al.[11]

Illness Perception: This was assessed using the Brief Illness Perception Questionnaire (B-IPQ). It is an eight-item instrument assessing cognitive and emotional perceptions of the illness, and in addition, nineth item is the casual item, which asks patients to list the three most important cancer-causing factors.[12] The questions were related to the following aspects: (i) consequences (how much does your illness affect your life?); (ii) timeline (how long do you think your illness will continue?); (iii) personal control (how much control do you feel you have over your illness?); (iv) treatment control (how much do you think your treatment can help your illness?); (v) identity (how much do you experience symptoms from your illness?); (vi) concern (how concerned are you about your illness?); (vii) coherence (how well do you feel you understand your illness?); and (viii) emotions (how much does your illness affect you emotionally?). Each question is rated on a linear 0-10 point scale. Higher scores indicate more negative illness representations, except for questions 3 , 4, and 7; higher scores indicate more positive illness perception. Differently, ninth item responses can be grouped into categories, such as stress, lifestyle, hereditary, determined by the particular illness studied. Categorical analysis can then be performed, either on just the top listed cause or all three listed causes. We used the Turkish version of the questionnaire form.[13]

\section{Statistic Analysis}

In the analysis of the data, descriptive statistics were used for demographic variables. The conformity of the variables to the normal distribution was examined by Kolmogorov-Smirnov and Shapiro Wilk tests and it was determined that all variables were not distributed normally. The Mann-Whitney U test was used to compare the two groups and Kruskal-Wallis analysis was used for three or more groups. Spearman correlation analysis was used for the correlation between variables. The strength of agreement is evaluated by correlation coefficient $(<0.00$ is poor; $0.00-0.20$ is slight, $0.21-0.40$ is fair, $0.41-0.60$ is moderate, $0.61-0.80$ is substantial, $0.81-1.00$ is almost perfect). A p-value $<0.05$ was considered to indicate statistical significant. Statistical analysis was performed using SPSS 22.0 software (SPSS, Chicago, IL, USA).

\section{Results}

A total of 182 patients involved in this study. The demographic and clinical characteristics of the participants are shown in Table 1. The mean age was 53.57 years (range, 22-87 years). There were 103 (56.59\%) female and $79(43.41 \%)$ male patients. At the time of the interview, the majority of patients were married $(n=152$, $83.52 \%)$. Their educational levels were low ( $81.3 \%$ were illiterate or primary school level). All patients were receiving intravenous chemotherapy. The majority of the patients had metastatic stage disease $(n=116,63.74 \%)$. Six of the patients were working. Breast and gastrointestinal tract cancer were the dominant diagnosis $(\mathrm{n}=55,30.22 \% ; \mathrm{n}=51,28.02 \%)$. With scores of 8 or above, we found that $51.1 \%$ of the sample to have possible clinical levels of anxiety, and $52.2 \%$ had possible clinical levels of depression (Table 1). According to the possible and probable distinction of clinical pathology, the present sample had possible clinical levels of anxiety and depression of $25.3 \%$ and $26.4 \%$, respectively, and probable clinical levels of anxiety and depression of $25.8 \%$ for both.

Table 2 was described as the VAS, positive and negative illness perception, anxiety and depression scores. The mean VAS scores were 3.6 (range, 0-10). According to B-IPQ, the mean positive IPQ scores were 21.02 (range, 7-30), negative IPQ scores were 27.29 (range, $0-50$ ). The mean anxiety scores were 7.87 (range, $0-19$ ), while for the depression, it was 7.96 (range, 0-20). As the educational level of the patients decreased, anxiety and depression scores increased ( $\mathrm{p}=0.019, \mathrm{p}=0.003$; respectively). While anxiety scores were high in female gender patients, there were no differences in depression scores $(p=0.009, p=0.062)$. There was no difference in anxiety and depression in terms of marital status, disease stage and diagnostic subgroups. According to VAS analyses, there was no correlation between VAS scores and education level, marital status, diagnosis subgroup and disease stage. VAS score was higher in the female patients $(\mathrm{p}=0.001)$. Patients with low education levels and the metastatic stage had a higher rate 
Table 1 Demographic and clinical characteristics of the patients $(n=182)$

\begin{tabular}{|c|c|}
\hline Characteristics & n (\%) \\
\hline \multicolumn{2}{|l|}{ Age } \\
\hline Median (range) & 5.57 (range, 22-87) \\
\hline \multicolumn{2}{|l|}{ Gender } \\
\hline Female & $103(56.59)$ \\
\hline Male & $79(43.41)$ \\
\hline \multicolumn{2}{|l|}{ Marital status } \\
\hline Single & $6(3.30)$ \\
\hline Divorced & $2(1.10)$ \\
\hline Widowed & $22(12.09)$ \\
\hline Married & $152(83.52)$ \\
\hline \multicolumn{2}{|l|}{ Educational level } \\
\hline Illiterate & $43(23.63)$ \\
\hline Primary school & $105(57.69)$ \\
\hline Secondary school & $25(13.74)$ \\
\hline University & $9(4.95)$ \\
\hline \multicolumn{2}{|l|}{ Diagnosis } \\
\hline Breast & $55(30.22)$ \\
\hline \multicolumn{2}{|l|}{ Gastrointestinal system (esophagus, } \\
\hline Lung & $27(14.84)$ \\
\hline Female genitourinary tract & $19(10.44)$ \\
\hline Male genitourinary tract & $13(7.14)$ \\
\hline Others (sarcoma, head-neck, melanoma) & a) $17(9.34)$ \\
\hline \multicolumn{2}{|l|}{ Stage } \\
\hline Early and localized & $66(36.26)$ \\
\hline Metastatic & $116(63.74)$ \\
\hline \multicolumn{2}{|l|}{ Working status } \\
\hline Yes & $6(3.30)$ \\
\hline No & $176(96.70)$ \\
\hline \multicolumn{2}{|l|}{ Anxiety score } \\
\hline 0-7: Normally & $89(48.9)$ \\
\hline 8-10: Possible & $46(25.3)$ \\
\hline 11-21: Probable & $47(25.8)$ \\
\hline \multicolumn{2}{|l|}{ Depression score } \\
\hline 0-7: Normally & $87(47.8)$ \\
\hline 8-10: Possible & $48(26.4)$ \\
\hline 11-21: Probable & $47(25.8)$ \\
\hline
\end{tabular}

of negative illness perception $(\mathrm{p}=0.006, \mathrm{p}=0.032$, respectively) (Table 3 ).

Positive illness perception parameters, such as (i) personal control (question 3-how much control do you feel you have over your illness?) and (ii) treatment control (question 4-how much do you think your treatment can help your illness?), were both not correlated with anxiety scores $(\mathrm{p}=0.120, \mathrm{p}=0.070$, respectively). According to the evaluation of depression scores, personal control was negatively correlated $(\mathrm{p}<0.005)$ and no relation was found with treatment control $(\mathrm{p}=0.062)$.
The mean score of coherence, which is a parameter of positive illness perception, was 7.51 (0 to 10). Coherence was not correlated with anxiety and depression scores. In contrast, the following were positively correlated with anxiety and depression scores $(\mathrm{p}<0.005$, for all): negative illness perception as (i) consequences (question 1-how much does your illness affect your life?), (ii) timeline (question 2-how long do you think your illness will continue?), (iii) identity (question 5-how much do you experience symptoms from your illness?), (iv) concern (question 6-how concerned are you about your illness?), and (v) emotions (question 8-how much does your illness affect you emotionally?). VAS was positively correlated with negative illness perception $(\mathrm{p}<0.005$, for all) and was not correlated with positive illness perception (Table 4).

\section{Discussion}

The objective of cancer treatment is to cure cancer, prolong life when cure is not possible, and give palliation. The overall impact of chemotherapy on cancer survival can be difficult to estimate since improved cancer screening, prevention strategies, and detection all influence statistics on cancer incidence and mortality. Although chemotherapy may prolong survival modestly in advanced cancer [14], conventional cytotoxic chemotherapy has proven unable to cure most cancers after they have metastasized. Cancer and its treatment may have a severe impact on individuals, affecting all areas of functioning, causing a variety of problems and affecting various quality of life (QOL) issues. In this study, we aimed to examine the correlation between illness perception, pain and distress during chemotherapy treatment in cancer patients.

Patients may experience anxiety and depression due to the negative effects of cancer and treatment. In this case, the individual's level of perception decreases, his/ her ability to share emotions and coping strategies decreases, social interaction and social support becomes difficult, patients' fighting power decreases and treatment response deteriorates over time. In one study, it was stated that the long duration and uncontrollable side effects of chemotherapy treatment increased the level of anxiety and depression and adversely affected the quality of life.[15]

The demographic characteristics of the patients are associated with anxiety and depression. In one study, it was reported that female patients had higher levels of anxiety than male patients.[16] In our study, the female sex anxiety rate was high $(\mathrm{p}=0.009)$. Depression 
Table 2 The pain visual analogue scale (VAS), positive and negative illness perception, anxiety and depression scores

\begin{tabular}{|c|c|c|c|c|c|}
\hline & Median & Mean & SD & Minimum & Maximum \\
\hline VAS & 4 & 3.59 & 2.93 & 0 & 10 \\
\hline Positive illness perception & 21 & 21.02 & 5.54 & 7 & 30 \\
\hline Negative illness perception & 28 & 27.29 & 12.22 & 0 & 50 \\
\hline Anxiety & 8 & 7.87 & 4.35 & 0 & 19 \\
\hline Depression & 8 & 7.95 & 4.40 & 0 & 20 \\
\hline
\end{tabular}

VAS: Visual analoge scale; SD: Standart deviation

Table 3 Association of the demographic and clinical characteristics of the patients with visual analogue scale (VAS), positive and negative illness perception, anxiety and depression scores

\begin{tabular}{|c|c|c|c|c|c|c|c|c|c|c|c|}
\hline \multirow[t]{2}{*}{ Characteristics } & \multirow[t]{2}{*}{$\mathbf{n}$} & \multicolumn{2}{|c|}{ VAS } & \multicolumn{2}{|c|}{ Anxiety } & \multicolumn{2}{|c|}{ Depression } & \multicolumn{2}{|c|}{ Positive B-IPQ } & \multicolumn{2}{|c|}{ Negative B-IPQ } \\
\hline & & Mean \pm SD & $\mathbf{p}$ & Mean \pm SD & $\mathbf{p}$ & Mean \pm SD & $\mathbf{p}$ & Mean \pm SD & $\mathbf{p}$ & Mean \pm SD & $\mathbf{p}$ \\
\hline \multicolumn{12}{|l|}{ Gender } \\
\hline Female & 103 & $4.23 \pm 2.87$ & 0.001 & $8.54 \pm 4.21$ & 0.009 & $8.50 \pm 4.29$ & 0.062 & $20.88 \pm 5.01$ & 0.601 & $28.19 \pm 11.80$ & 0.299 \\
\hline Male & 79 & $2.77 \pm 2.82$ & & $7.00 \pm 4.41$ & & $7.24 \pm 4.49$ & & $21.20 \pm 6.19$ & & $26.11 \pm 12.72$ & \\
\hline \multicolumn{12}{|l|}{ Marital status } \\
\hline Married & 152 & $3.63 \pm 2.94$ & 0.803 & $7.74 \pm 4.21$ & 0.543 & $7.78 \pm 4.48$ & 0.136 & $20.91 \pm 5.62$ & 0.527 & $26.89 \pm 12.38$ & 0.291 \\
\hline $\begin{array}{l}\text { Single, divorced } \\
\text { or widowed }\end{array}$ & 30 & $3.47 \pm 2.92$ & & $8.53 \pm 5.06$ & & $8.87 \pm 3.96$ & & $21.57 \pm 5.16$ & & $29.33 \pm 11.33$ & \\
\hline \multicolumn{12}{|l|}{ Educational level } \\
\hline Illiterate & 43 & $3.95 \pm 3.18$ & 0.708 & $8.81 \pm 4.52$ & 0.019 & $9.28 \pm 4.35$ & 0.003 & $19.60 \pm 5.12$ & 0.090 & $31.33 \pm 13.56$ & 0.006 \\
\hline Primary school & 105 & $3.52 \pm 2.86$ & & $8.01 \pm 4.36$ & & $8.08 \pm 4.31$ & & $21.18 \pm 5.73$ & & $26.74 \pm 11.70$ & \\
\hline $\begin{array}{l}\text { Secondary school } \\
\text { and university }\end{array}$ & 34 & $3.38 \pm 2.88$ & & $6.26 \pm 3.78$ & & $5.91 \pm 4.17$ & & $22.32 \pm 5.18$ & & $23.88 \pm 10.94$ & \\
\hline \multicolumn{12}{|l|}{ Diagnosis group } \\
\hline Breast & 55 & $4.11 \pm 3.05$ & 0.165 & $8.49 \pm 4.36$ & 0.585 & $8.35 \pm 4.62$ & 0.321 & $21.75 \pm 4.32$ & 0.585 & $26.76 \pm 11.80$ & 0.280 \\
\hline Lung & 27 & $3.85 \pm 2.64$ & & $6.78 \pm 4.48$ & & $8.33 \pm 5.01$ & & $21.48 \pm 5.81$ & & $28.93 \pm 12.49$ & \\
\hline GIS & 51 & $2.90 \pm 2.71$ & & $7.88 \pm 4.00$ & & $7.55 \pm 3.87$ & & $21.10 \pm 6.37$ & & $26.78 \pm 12.62$ & \\
\hline Female genitouinary & 19 & $4.32 \pm 2.75$ & & $8.21 \pm 4.12$ & & $9.58 \pm 4.38$ & & $19.74 \pm 5.36$ & & $32.11 \pm 12.60$ & \\
\hline Male genitourinary & 13 & $3.77 \pm 3.79$ & & $6.92 \pm 5.27$ & & $6.38 \pm 4.41$ & & $19.69 \pm 5.53$ & & $24.62 \pm 13.09$ & \\
\hline Others & 17 & $2.71 \pm 2.89$ & & $7.94 \pm 4.87$ & & $6.71 \pm 4.01$ & & $20.18 \pm 6.42$ & & $24.59 \pm 10.68$ & \\
\hline \multicolumn{12}{|l|}{ Staging group } \\
\hline Early and localised & 66 & $3.03 \pm 2.79$ & 0.056 & $8.06 \pm 4.07$ & 0.742 & $7.61 \pm 3.93$ & 0.582 & $21.95 \pm 5.27$ & 0.053 & $25.41 \pm 10.53$ & 0.032 \\
\hline Metastatic & 116 & $3.92 \pm 2.97$ & & $7.77 \pm 4.52$ & & $8.16 \pm 4.66$ & & $20.49 \pm 5.64$ & & $28.36 \pm 13.01$ & \\
\hline
\end{tabular}

p: Statistically significant values $(\mathrm{p}<0.005)$ were shown as italic; SD: Standard deviation; VAS: Visual analoge scale; IPQ: IIIness Perception Questionnaire

was not statistically significant concerning gender ( $\mathrm{p}=0.062$ ). Regarding social support, the likelihood of being married had a positive effect on anxiety and depression. In our study, although the scoring was higher in the unmarried group than married group (anxiety: $8.53 \pm 5.06$ versus $7.74 \pm 4.21$, depression: $8.87 \pm 3.96$ versus $7.78 \pm 4.48)$, no statistically significant difference was found ( $\mathrm{p}=0.543, \mathrm{p}=0.136$, respectively).

The level of education was also an important factor. In one study, patients with low-level education had a higher prevalence of depression than patients with over six years of education ( $\mathrm{p}<0.001)$. [17] In our study, anxiety and depression rates were higher in the illiterate group (anxiety: $8.81 \pm 4.52$, depression: $9.28 \pm 4.35$ ) and statistically significant differences were found ( $\mathrm{p}=0.019, \mathrm{p}=0.003$, respectively).

Unlike other studies $[4,18]$, the present study failed to the difference in anxiety and depression depending on the type of cancer. Failing to see differences in the type of cancer in our study was surprising but might be explained by the variability within the sample, representing diverse types of cancer resulting in few cases behind each group.

The prevalence rates of depression/anxiety may be different in patients with different tumor sites. Some researchers have suggested that patients with breast and lung cancers have a high risk of depression.[19] Symptoms of depression were found to occur in 3-55\% 
Table 4 Correlation of Brief IIIness Perception Questionnaire (B-IPQ), Visual Analoge Scale (VAS) with anxiety and depression score: Spearman's rho correlation test

\begin{tabular}{|c|c|c|c|c|c|c|}
\hline & \multicolumn{2}{|c|}{ VAS } & \multicolumn{2}{|c|}{ Anxiety } & \multicolumn{2}{|c|}{ Depression } \\
\hline & $\mathbf{r}^{\prime}$ & $\mathbf{p}$ & $\mathbf{r}^{\prime}$ & $\mathbf{p}$ & $\mathbf{r}^{\prime}$ & $\mathbf{p}$ \\
\hline Consequences & $0.345^{* *}$ & $<0.001$ & $0.353^{* *}$ & $<0.001$ & $0.399 * *$ & $<0.001$ \\
\hline Timeline & $0.228^{* *}$ & 0.002 & $0.240^{* *}$ & 0.001 & $0.292^{* *}$ & $<0.001$ \\
\hline Personal control $^{\mathrm{a}}$ & -0.079 & 0.290 & -0.116 & 0.120 & $-0.213^{* *}$ & 0.004 \\
\hline Treatment control $^{\mathrm{a}}$ & $-0.191^{* *}$ & 0.010 & -0.135 & 0.070 & -0.139 & 0.062 \\
\hline Identity & $0.511^{* *}$ & $<0.001$ & $0.468^{* *}$ & $<0.001$ & $0.482^{* *}$ & $<0.001$ \\
\hline Concern & $0.371^{* *}$ & $<0.001$ & $0.516^{* *}$ & $<0.001$ & $0.568^{* *}$ & $<0.001$ \\
\hline Coherence $^{a}$ & -0.026 & 0.729 & 0.037 & 0.616 & 0.082 & 0.270 \\
\hline Emotional representation & $0.284^{* *}$ & $<0.001$ & $0.482^{* *}$ & $<0.001$ & $0.513^{* *}$ & $<0.001$ \\
\hline
\end{tabular}

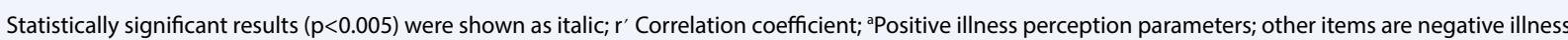
perception parameters; ${ }^{* *}$ Correlation is significant at the 0.01 level; ${ }^{*}$ Correlation is significant at the 0.05 level

of the breast cancer patients, while anxiety was found in $18-33 \%$.[20] In another study, the depression prevalence was high in lung, esophagus and cervix cancer. [17] In our study, the patients with breast and female genitourinary tract cancers had a high risk of anxiety and depression scores. This result may be due to the concern of women's sexuality loss of function.

Disease stage was not influenced neither anxiety $(\mathrm{p}=0.742)$ nor depression $(\mathrm{p}=0.582)$. Most of the $\mathrm{pa}-$ tients did not know their disease stages, which may explain that anxiety and depression were not influenced by the disease stage because information about patients' disease stage was obtained from their medical records.

The pain is affected by the individual's life experiences. People with negative thoughts about cancer pain may have more severe pain. Emotional reactions occur due to social isolation. All these changes result in increased stress levels, tension, anger and pain.[5] In our study, only gender differences were found concerning demographic characteristics and pain $(\mathrm{p}=0.001)$. Pain scores were higher in patients with anxiety and depression scores of 11 and more (Mean score 5.13 \pm 3.17 , $4.89 \pm 2.98$, respectively, for both $\mathrm{p}=0.001$ ).

Illness perception has been linked to depressive symptoms. In a sample of colorectal cancer patients, the authors found that individuals who attributed a higher number of symptoms to their illness (identity), held more negative beliefs regarding the timeline of their illness, endorsed more perceived consequences, and reported lower treatment control were at increased risk for depressive symptoms. Similar relationships between illness perception and depressive symptoms have been documented in advanced cancer patients. [6] In another study with breast cancer patients, the illness perception had a significant effect on anxiety and depression.[21] We found the same correlation in our study. Patients who had a lower positive illness perception exhibited more anxiety and depression. Coherence, one of the positive illness perception items, was a generally high score in our patient $(7.51 \pm 3.06)$. When the patients felt that they understood their illness sufficiently, they gave a high score, which means the sense of positive disease as in personal and treatment control. Understanding the disease is important to cope with the disease. In our study, there was no significant correlation between coherence and anxiety and depression. This may be related to our precision to provide information that leads to understanding their illnesses at a high level. As a different situation, patients with higher negative illness perception scores showed higher anxiety and depression scores. In this context, it was found that the illness perception in patients receiving chemotherapy had a significant effect on anxiety and depression.

Our study has several limitations. First, this study was designed the cross-sectionally, and for this reason, the cancer patients were seen at one point in time. Second, the mixed convenience sample was included in this study, and there was a variety of cancer diagnoses. This could be problematic because cancer encompasses a diverse array of illnesses with the particular difficulties patients face varying across cancer sites. Third, the majority of patients had a low educational level. Thus, we cannot generalize the findings obtained in this study.

\section{Conclusion}

Anxiety and depression were strongly associated with illness perception, pain and educational level in cancer 
patients during chemotherapy treatment. Oncologists and chemotherapy nurses should pay more attentive to the signs and symptoms of anxiety and depression and offer specific supportive therapy to each patient.

Peer-review: Externally peer-reviewed.

Conflict of Interest: The authors declare that they have no conflict of interest.

Ethics Committee Approval: The protocol and informed consent documentation were reviewed and approved by the Independent Ethics Committee of the University and agreed with the ethical principles of the Declaration of Helsinki.

Financial Support: Financial and material support was not recevied.

Authorship contributions: Concept - H.Y.Ç., G.E.; Design - H.Y.Ç., G.E.; Supervision - H.Y.Ç., G.E.; Funding - H.Y.Ç.; Materials - H.Y.Ç.; Data collection and/or processing - H.Y.Ç.; Data analysis and/or interpretation - H.Y.Ç.; Literature search - H.Y.Ç.; Writing - H.Y.Ç.; Critical review - H.Y.Ç., G.E.

\section{References}

1. Mitchell AJ, Chan M, Bhatti H, Halton M, Grassi L, Johansen $\mathrm{C}$, et al. Prevalence of depression, anxiety, and adjustment disorder in oncological, haematological, and palliative-care settings: a meta-analysis of 94 interview-based studies. Lancet Oncol 2011;12(2):160-74.

2. Smith HR. Depression in cancer patients: Pathogenesis, implications and treatment (review). Oncol Lett 2015;9(4):1509-14.

3. Walker J, Hansen $\mathrm{CH}$, Martin $\mathrm{P}$, Symeonides $\mathrm{S}$, Ramessur R, Murray G, et al. Prevalence, associations, and adequacy of treatment of major depression in patients with cancer: a cross-sectional analysis of routinely collected clinical data. Lancet Psychiatry 2014;1(5):343-50.

4. Linden W, Vodermaier A, Mackenzie R, Greig D. Anxiety and depression after cancer diagnosis: prevalence rates by cancer type, gender, and age. J Affect Disord 2012;141(2-3):343-51.

5. Çapar SG. Kemoterapi gören kanserli hastalarda ağrı ile anksiyete depresyon arasındaki ilişkinin değerlendirilmesi. Trakya Üniversitesi, Yüksek Lisans Tezi. 2010.

6. Gray NM, Hall SJ, Browne S, Johnston M, Lee AJ, Macleod U, et al. Predictors of anxiety and depression in people with colorectal cancer. Support Care Cancer 2014;22(2):307-14.

7. Buick DL. Illness representations and breast cancer: coping with radiation and chemotherapy. In: Petrie KJ, Weinman JA, eds. Perceptions of Health and Illness.
Amsterdam, The Netherlands: Harwood Academic Publishers;1997. p. 379-409.

8. Wilkie D, Lovejoy N, Dodd M, Tesler M. Cancer pain intensity measurement: concurrent validity of three tools-finger dynamometer, pain intensity number scale, visual analogue scale. Hosp J 1990;6(1):1-13.

9. Snaith RP, Zigmond AS. The Hospital Anxiety and Depression Scale. Acta Psychiatrica Scandinavia 1983;67(6):361-70.

10. Smith AB, Selby PJ, Velikova G, Stark D, Wright EP, Gould A, et al. Factor analysis of the Hospital Anxiety and Depression Scale from a large cancer population. Psychol Psychother 2002;75(Pt 2):165-76.

11. Aydemir Ö, Güvenir T, Küey L, Kültür S. Validity and Reliability of Turkish Version of Hospital Anxiety and Depression Scale. Turkish J Psychiatry1997;8(4):280-7.

12. Broadbent E, Petrie KJ, Main J, Weinman J. The brief illness perception questionnaire. J Psychosom Res 2006;60(6):631-7.

13. Kocaman N, Özkan M, Armay Z, Özkan S. The reliability and the validity study of Turkish adaptation of the revised Illness Perception Questionnaire. Anatol J Psychiatry 2007;8(4):271-80.

14. Ragnhammar P, Hafström L, Nygren P, Glimelius B; SBU-group. Swedish Council of Technology Assessment in Health Care. A systematic overview of chemotherapy effects in colorectal cancer. Acta Oncologica 2001;40(2-3):282-308.

15. Beser NG, Öz F. Anxiety-Depression Levels and Quality of Life of Patients with Lymphoma who are Curing Chemotherapy. J Cumhuriyet Uni Sch Nurs 2003;7:47-58.

16. Alacacıoğlu A, Yavuzşen T, Diriöz M, Yeşil L, Bayrı D, Yılmaz U. Changes in Anxiety Levels Patients with Cancer Receiving Chemotherapy. UHOD 2007;2(17):87-93.

17. Hong JS, Tian J. Prevalence of anxiety and depression and their risk factors in Chinese cancer patients. Support Care Cancer 2014;22(2):453-9.

18. Ganz PA, Moinpour CM, Pauler DK, Kornblith AB, Gaynor ER, Balcerzak SP, et al. Health status and quality of life in patients with early-stage Hodgkin's disease treated on southwest oncology group study 9133. J Clin Oncol 2003;21(18):3512-9.

19. Massie MJ. Prevalence of depression in patients with cancer. J Natl Cancer Inst Mnogr 2004;(32):57-71.

20. Somerset W, Stout SC, Miller AH, Musselman D. Breast cancer and depression. Oncology (Williston Park) 2004;18(8):1021-34.

21. Kus T, Aktas G, Ekici H, Elboga G, Djamgoz S. Illness perception is a strong parameter on anxiety and depression scores in early-stage breast cancer survivors: a single-center cross-sectional study of Turkish patients. Support Care Cancer 2017;25(11):3347-55. 